\title{
Effect of Moisture Content on Aflatoxin B1 Production in Wheat Flour Samples Collected from Lahore, Pakistan
}

\author{
Naseem Zahra ${ }^{* 1}$, Ayesha Idrees ${ }^{1,2}$, Muhammad Aslam², Zahra Noreen ${ }^{2}$, \\ Shahid Masood ${ }^{1}$, Muhammad Khalid Saeed ${ }^{1}$, Imran Kalim ${ }^{1}$, Alim-un-Nisa ${ }^{1}$, \\ Sajila Hina ${ }^{1}$, Ijaz Ahmad ${ }^{1}$, Muhmamad Ashraf ${ }^{1}$, Mahnoor Razzaq ${ }^{2}$ and \\ Saba Zain-ul-Abideen ${ }^{2}$ \\ ${ }^{1}$ Pakistan Council of Scientific and Industrial Research Laboratories Complex, Ferozepur Road, Lahore, Pakistan. \\ ${ }^{2}$ Univesrity of Education, Township Campus, Lahore, Pakistan. \\ *Corresponding Author Email: naseem.zahra1981@gmail.com \\ Received 21 December 2018, Revised 09 December 2019, Accepted 25 December 2019
}

\begin{abstract}
The present research was conducted to study the effects of moisture contents on the level of aflatoxin B1 (AFB1) in wheat flour samples collected from different areas of Lahore. Total 30 samples were collected from different locations and shops in Lahore- Pakistan, making sure that they have different levels of moisture contents. Thin layer chromatography technique was (TLC) selected to check the AFB1 contamination levels in wheat flour samples. The AFB1 was detected in 10 samples $(33.33 \%)$, out of which 7 samples (23.33\%) had AFB1 levels within permissible range, i.e. $2 \mu \mathrm{g} / \mathrm{kg}$, while 3 samples (10\%) contained AFB1 levels i.e. $2.67 \mu \mathrm{g} / \mathrm{kg}, 2.93 \mu \mathrm{g} / \mathrm{kg}, 3.01$ $\mu \mathrm{g} / \mathrm{kg}$ above permissible range. From the study it was concluded that the contaminated samples had greater moisture contents than that of non contaminated samples. Sample with $35 \%$ moisture content has $3.01 \mu \mathrm{g} / \mathrm{kg}$ AFB1 levels. The food stuff can be protected from AFB1 production by minimizing the moisture contents, the lesser the moisture content, the lesser will be the aflatoxin levels in food samples.
\end{abstract}

Keywords: Aflatoxin B1; Wheat flour; TLC, Moisture

\section{Introduction}

Food safety is essential for the human health. It's the responsibility of every human being to take healthy food to ensure good health. The same thought is applied to cereal industry of Pakistan as it is an agro based country [1]. Because of the poor harvesting practices as well as the bad storage conditions, the cereal industry of developing countries like Pakistan is facing a lot of challenges. Most of the food stuffs are being spoiled due to the proliferation of fungi mycelium in the grains that produce toxins [2]. Due to the cereal grain invasion by fungi, the contamination risk by mycotoxins is considerably increasing. Some mycotoxins exert toxic effects on both human and animal health which are constantly increasing. The legislative provision is taken to control their presence in food and feed [3]. A major class of these mycotoxins also include aflatoxins. Aflatoxins are in fact toxic and carcinogenic metabolites, generated by certain species of Aspergillus, predominantly Aspergillus flavus and Aspergillus parasiticus. Acute hepatitis and immune-suppression are some of the toxic effects of these metabolites. Aflatoxin consumption is causing serious health risks in animals including humans which are well documented by the International Agency for Research on Cancer (IARC). This agency has designated the aflatoxin as one of the virulent carcinogens, mainly affecting liver [4]. Up to 20 different classes of aflatoxin are known. The most 
eminent types include aflatoxins AFB1, AFB2, AFG1, AFG2, AFM1, and AFM2 [5]. In crops, the mycotoxin contamination occurs either at the field level or at some stage during storage. The production of aflatoxin is mainly because of two main factors, i.e. improper control of temperature and moisture contents [6]. The level of contamination due to aflatoxin production in some cereals, produced in Pakistan, has been studied. The results gave different percentages of aflatoxins in different commodities [7]. The contamination level was observed in wheat sample $(15.5 \mu \mathrm{g} / \mathrm{kg})$, maize sample $(13.0 \mu \mathrm{g} / \mathrm{kg})$ and barley sample $(12.6 \mu \mathrm{g} / \mathrm{kg})$. Pakistan's economy is largely based on agricultural crops like wheat [8]. Numerous studies were conducted to evaluate aflatoxin contamination in wheat grains and wheat flour samples. Over 366 food samples have been analyzed by Caldas in year 2002 including rice, cereals and peanuts. In the report $19.6 \%$ samples were found to have aflatoxin contamination [9]. AFB1 is considered as one of the most toxic hepatocarcinogen for mammals and it is classified by IARC as Group 1 carcinogen. In one study out of 352 cereal samples, AFB1 was detected in $8.8 \%$ at concentration below $26 \mathrm{ng} / \mathrm{g}$ [10]. Halt detected AFB1 in wheat samples and found the level of contamination to be $16.3 \mathrm{ng} / \mathrm{g}$ [11]. More commonly, the mycotoxins are found to occur during tropical conditions. So, most of the developing countries are known to have crops that are liable to be influenced with mycotoxins. As these mycotoxins are causing serious, long term health risks which therefore are chiefly being widespread in developing countries. This study is designed to determine AFB1 in different wheat flour samples, having different levels of moisture contents collected from different areas of Lahore, intended for human consumption.

\section{Materials and Methods Collection of Samples}

Like other developing countries, the Pakistani people are also using the wheat flour from different sources, like home-made and commercial flour [12]. In the present work, 30 samples of three different types of wheat flour samples were collected. 10 samples of each category were collected from a. different local shops (commercially prepared wheat flour), b. homes where the flour was being made with aircleaned wheat, c. houses where the wheat is washed and dried in sunlight before grinding to make flour. Before commencing with the research work, these collected samples were stored in dry and cool place in properly sealed synthetic polythene bags for two months at room temperature from August to September 2018 until they were used for aflatoxin analysis. Aflatoxins level in extracted wheat flour samples was assessed by comparison with aflatoxin standards of varying concentrations [13].

\section{Sampling of Wheat Flour}

The present research study was conducted at Food and Biotechnology Research Centre of PCSIR Laboratories Complex, Lahore. Aflatoxins, if present, are distributed non-uniformly in the food stuff. The contaminated samples may have relatively high level of aflatoxin as aflatoxin distribution is diverse. To obtain vivid results, a suitable sampling procedure was properly planned beforehand. All wheat flour samples were put in the air tight and completely sealed plastic bags. To acquire the most suitable and representative portion for particular flour, about $500 \mathrm{~g}$ of each wheat flour sample was collected. It was also made sure that each sample was taken from four different corners of the stored bag or container. The amount of Wheat flour was reduced to $200 \mathrm{~g}$ each by passing the samples through the sample divider. It was done to acquire better homogeneity. After that, the wheat flour samples were mixed properly making a fine, homogenous mixture [13].

\section{Moisture Test}

As the samples collected were of three types with different exposure to water, so it was essential to determine their moisture contents before proceeding to the experimental work. For this, round about $2 \mathrm{~g}$ of each sample was taken on the petri dish and it was placed in the oven for $8 \mathrm{~h}$ at $105{ }^{\circ} \mathrm{C}$ to remove all the moisture contained in it. The moisture percentage was determined by subtracting the weight of sample after drying from the original weight of the sample [14]. 


\section{Extraction of Aflatoxins from Wheat Flour} Samples

Various analytical methods for extraction are being used to detect aflatoxin in different type of stuff due to their varying chemical composition. Generally, there is not any specific method for aflatoxin detection which is used for the wheat flour samples. However, the chloroform extraction method was finally decided to be used for the extraction of aflatoxins from collected samples. The aflatoxins' level in the wheat flour samples was determined with highly sensitive, time saving and easiest TLC technique [15]. The extraction of AFB1 was done to analyze the wheat flour samples. The extraction was done by taking $50 \mathrm{~g}$ of wheat flour sample in a $500 \mathrm{~mL}$ Erlenmeyer flask. The sample was then soaked using about $25 \mathrm{~mL}$ of water. Meanwhile, about $150 \mathrm{~mL}$ of chloroform was poured in the same flask. By using wristaction shaker, the flask was shaken for 30 minutes. After that, the wheat flour sample was filtered using Whatman filter paper no. 1.1 around $50 \mathrm{~mL}$ of that filtrate was taken in a beaker and kept on the hotplate to dry [16]. For spotting on TLC plates, the dilution was taken in micro-litres. To apply the test solution on TLC plates, $25 \mu \mathrm{L}$ was taken by using a micro-syringe. Careful spotting was made sure to obtain vivid results. 5-10 $\mu \mathrm{L}$ standard solution of AFB1 was spotted sidewise on the same plate.

The dilutions were obtained in micro-litres for TLC spotting. A spot of $25 \mu \mathrm{L}$ of the test solution was applied on a TLC Plate using a micro syringe. To work as internal standards, $5 \mu \mathrm{L}$ and $10 \mu \mathrm{L}$ standard spots of (aflatoxins) AFB1, AFB2, $\mathrm{AFG} 1$, and $\mathrm{AFG} 2$ were also spotted on that plate. About $40 \mathrm{~mL}$ of anhydrous ether (first mobile phase) was taken in the TLC tank and the spotted TLC plate was placed in it until the solvent had travelled up to half way. The plate was taken out and air dried after the fine development of the TLC plate. The same TLC plate was redeveloped in TLC tank containing $5 \mathrm{~mL}$ of acetone and $45 \mathrm{~mL}$ chloroform (1:9 by volume). After the removal of TLC plate from the tank, air-dried and carefully observed the test solution spot to confirm the presence or absence of AFB1 using UV lamp. Likewise, some new concentrations of the test solution were also prepared for spotting in case if the first plate showed necessity for it [17].

\section{Detection of Wheat Flour Samples}

The spots' Fluorescence intensities of extracted wheat flour samples were keenly observed as well as compared with the standard spots of AFB1. If the standard spots were equally displaced from the fluorescing spot of the wheat flour sample, then the average of the two standard spots was taken into consideration.

\section{Confirmation of the Results}

The aflatoxin AF of the sample spots is one of the most significant steps for aflatoxins' analysis. It was carried out by using a fine, homogenous spray of aqueous sulphuric acid $(50 / 50 \mathrm{v} / \mathrm{v})$ on the TLC plate which was dried and carefully observed under the UV Light of $365 \mathrm{~nm}$ wavelength [16].

\section{Calculations}

The AFB1 concentration $(\mu \mathrm{g} / \mathrm{kg})$ in wheat flour samples was calculated with the help of below formula:

Aflatoxins' level $(\mu \mathrm{g} / \mathrm{kg})=\mathrm{S} \times \mathrm{Y}$ x V / W x Z

Where;

$\mathrm{S}=$ the volume of aflatoxin std. used for spotting $(\mu \mathrm{L})$

$\mathrm{Y}=$ concentration of aflatoxins given in reference standard $(\mu \mathrm{g} / \mathrm{mL})$

$\mathrm{V}=$ the Vol. of chloroform used to dissolve the dried aflatoxin

$\mathrm{Z}=$ Volume of sample extract for spotting

$\mathrm{W}=$ Effective weight of original sample in final extract $(\mathrm{g})$

\section{Results and Discussion}

Wheat flour is an extremely hygroscopic matter and temperature changes its moisture levels during storage. Moisture content of wheat flour is important with regards to shelf life, lower the wheat flour moisture, the improved would be storage constancy [18]. Wheat grain and flour 
contamination with aflatoxins has been described in many studies [19]. The moisture variation can be depicted as follows in Fig. 1.

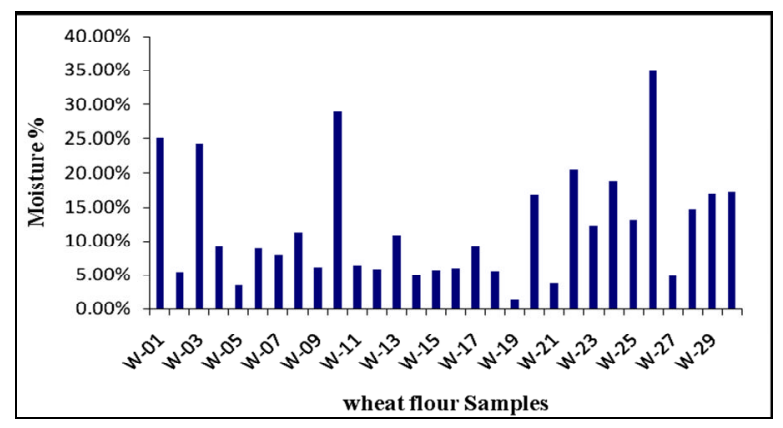

Figure 1. Analysis of moisture contents in wheat flour

The present research clearly shows the effect of moisture contents on AFB1 production. Total 10 samples out of 30 were found contaminated with AFB1. In contaminated samples moisture levels was greater than $13 \%$. In 7 samples out of total 10 contaminated samples, the AFB 1 contamination was found within permissible limits i.e. $2 \mu \mathrm{g} / \mathrm{kg}$. However, samples W-1, W-10 and W26 were found contaminated with AFB1 beyond permissible levels. The results of AFB1 determination in wheat flour samples are given in Table 1.

Table 1. Determination of Aflatoxin B1 in wheat flour.

\begin{tabular}{lccc}
\hline $\begin{array}{l}\text { Sample } \\
\text { ID }\end{array}$ & $\begin{array}{c}\text { Aflatoxin B1 } \\
(\boldsymbol{\mu g} / \mathbf{k g})\end{array}$ & $\begin{array}{c}\text { Sample } \\
\text { ID }\end{array}$ & $\begin{array}{c}\text { Aflatoxin B1 } \\
(\boldsymbol{\mu} \mathbf{g} / \mathbf{k g})\end{array}$ \\
\hline W-1 & 2.67 & W-16 & Not Detected \\
W-2 & Not Detected & W-17 & Not Detected \\
W-3 & 1.97 & W-18 & Not Detected \\
W-4 & Not Detected & W-19 & Not Detected \\
W-5 & Not Detected & W-20 & 1.93 \\
W-6 & Not Detected & W-21 & Not Detected \\
W-7 & Not Detected & W-22 & 1.83 \\
W-8 & Not Detected & W-23 & Not Detected \\
W-9 & Not Detected & W-24 & 1.85 \\
W-10 & 2.93 & W-25 & Not Detected \\
W-11 & Not Detected & W-26 & 3.01 \\
W-12 & Not Detected & W-27 & Not Detected \\
W-13 & Not Detected & W-28 & 1.91 \\
W-14 & Not Detected & W-29 & 1.89 \\
W-15 & Not Detected & W-30 & 1.95 \\
\hline
\end{tabular}

The results matched with Borut and Joffe [20] who observed a relationship between aflatoxin contamination and moisture in wheat flour samples. The moist conditions cause more aflatoxin contamination in wheat flour samples [21]. Correspondingly, Hussaini et al., studied the relation of moisture and aflatoxins production in sorghum [22] and it was found that sorghum kept in the moist atmosphere was highly contaminated by A. flavus than that of sorgum kept in the dry conditions. The percentage analysis of AF B1 contamination in wheat flour is given in Fig. 2.

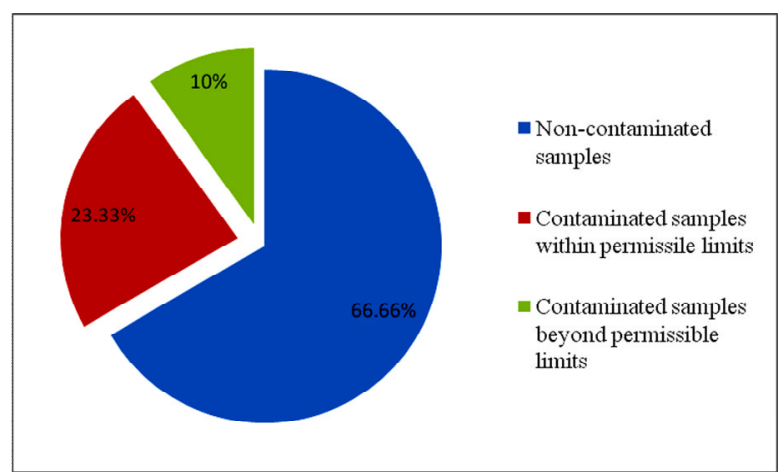

Figure 2. Percentage analysis of Aflatoxin B1 analysis in wheat flour

In a study conducted on newly harvested and remoistened corn, it was found that various moisture contents at different temperatures during storage have produced aflatoxin contents periodically. High moisture and warmer environment favors the production of aflatoxins by Aspergillus species [23]. Storage fungi like Aspergillus grow maximally at $13 \%$ moisture or $65 \%$ relative humidity while water activity, $\mathrm{a}_{\mathrm{w}}$, of 0.65 [24]. However, at $77 \%$ or above the optimum growth and proliferation take place. AlDefiery and Merjan [25] concluded from their study that $A$. flavus grew in wheat flour samples at maximum level after 3 months of storage at $10.7 \%$ humidity while in present study moisture of $35 \%$ maximum AFB1 contamination was found.

\section{Conclusion}

The AFB1 production increases if the stuff is not stored properly. Usually, wheat flour in Pakistan is stored in iron containers which is safe method and prevent it from being contaminated by 
AFB1 because it prevents the stuff from moisture. Here in this study $33.33 \%$ samples were contaminated with AFB1, so special care should be taken during storage of flour. The studies show that the air tight storage containers are safer than that of usual sacks used in market.

\section{References}

1. N. Zahra, N. Jamil, S. R. Ahmad, S. Munir, M. K. Saeed and I. Kalim, Transylv. Rev., 25 (2017) 4507.

http://transylvanianreviewjournal.org/index.p $\mathrm{hp} / \mathrm{TR} /$ article/view/1067

2. S. Vasanthi, S., Mycotoxin food safety risk in developing countries, International Food Policy Research Institute (IFPRI), 10 (2003) 3. https://core.ac.uk/download/pdf/48024116.p df

3. A. Aydin, U. Gunsen and S. Demirel, $J$. Food Drug Anal., 16 (2008) 48. https://www.researchgate.net/profile/Ali_Ay din7/publication/228669780_Total_Aflatoxi n_Aflatoxin_B_1_and_Ochratoxin_A_Level s_in_Turkish_Wheat_Flour/links/0c96051c4 18fd15625000000.pdf

4. A. Nisa, N. Zahra, S. Hina, R. Hayat and N. Ejaz, Pak. J. Sci. Ind. Res., 56 (2013) 98. 159-Article Text-308-1-10-20180611 (1)

5. A. Ismail, B.L. Gonçalves, D.V. de Neeff, B. Ponzilacqua, C.F. Coppa, H. Hintzsche, M. Sajid, A. G. Cruz, C. H. Corassin and C. A. Oliveira, Food Res. Int., 113 (2018) 74. https://doi.org/10.1016/j.foodres.2018.06.06 $\underline{7}$

6. I. Styriak, E. Conkova, A. Laciakova and J. Böhm, Animal Sci.-UZPI (Czech Republic), 43 (1998) 449. http://agris.fao.org/agrissearch/search.do?recordID=CZ1998001335

7. G. Lutfullah and A. Hussain, Food Control, 23 (2012) 32.

https://doi.org/10.1016/j.foodcont.2011.06.0 $\underline{04}$

8. N. Iqbal, K. Bakhsh, A. Maqbool and A.S. Ahmad, J. Agric. Social Sci., 1 (2005) 120. http://www.academia.edu/download/451307 23/Use of the ARIMA Model for Foreca sting W20160427-30899-clo.pdf
9. E. D. Caldas, S. C. Silva and J. N. Oliveira, Revista de Saúde Pública, 36 (2002) 319. https://doi.org/10.1590/S003489102002000300010

10. A. Ayalew, H. Fehrmann, J. Lepschy, R. Beck and D. Abate, Mycopathologia, 162 (2006) 57. https://doi.org/10.1007/s11046$\underline{006-0027-8}$

11. N. Taheri, S. Semnani, G. Roshandel, M. Namjoo, H. Keshavarzian, A.G. Chogan, F.G., Kebria and H. Joshaghani, Iran. J. Public Health, 41 (2012) 42.

https://www.ncbi.nlm.nih.gov/pubmed/2319 $\underline{3505}$

12. M. Holcomb, D.M. Wilson, M.W. Trucksess and H.C. Thompson, J. Chromatogr. A, 624 (1992) 341.

https://doi.org/10.1016/00219673(92)85687-O

13. A. Nisa, N. Zahra and S. Hina, Bangla. $J$. Sci. Ind. Res., 49 (2014) 189.

https://doi.org/10.3329/bjsir.v49i3.22134

14. H. G. Chang and P. Markakis, Cereal Chem., 58 (1981) 89.

https://doi.org/10.1016/j.jcs.2013.03.016

15. AOAC, Official Methods of Analysis, Association of Official Analytical Chemists, 18th Edition, Washington DC, USA (2005). https://www.scirp.org/(S(351jmbntvnsjtlaad kposzje))/reference/ReferencesPapers.aspx? ReferenceID=2033299

16. A. Nisa, N. Zahra and N.B. Yasha, Int. Food Res. J., 23 (2016) 243.

http://www.ifrj.upm.edu.my/volume-232016.html

17. N. Alim, N. Zahra, S. Firdous, N. Ejaz and S. Hina, Pak. J. Sci. Ind. Res. 55 (2012) 27. https://v2.pjsir.org/index.php/biologicalsciences/article/view/177

18. M. S. Butt, M. Nasir, S. Akhtar and K. Sharif, Internet J. Food Safety, 4 (2002) 1. https://www.academia.edu/1115972/Internet Journal_of_Food_Safety

19. H. B. Razdari, A. C. Nosrati, N. Ghaemi and S. M. Ara, Bull. Environ. Pharmacol. Life Sci., 3 (2014) 237.

https://pdfs.semanticscholar.org/6794/7f86b5 8b5c0824fe1502d36dd498b10b5683.pdf

$20 . \quad$ J. W. Dorner and R. J. Cole, J. Stored Prod. Res., 38 (2002) 329. 
https://doi.org/10.1016/S0022-

474X(01)00035-2

21. J. M. Milani, Veterinarni Medicina, 58 (2013) 405.

https://doi.org/10.17221/6979-VETMED

22. A. M. Hussaini, A. G. Timothy, H. A. Olufunmilayo, A. S. Ezekiel, and H. O. Godwin, World J. Agric. Sci., 5 (2009) 5. http://citeseerx.ist.psu.edu/messages/downlo adsexceeded.html

23. H. L. Trenk and P. A. Hartman, Appl. Microbiol., 19 (1970) 781.

https://aem.asm.org/content/19/5/781.short
24. A. Abdel-Hadi, D. Carter and N. Magan, J. Appl. Microbiol., 109 (2010) 1914. https://doi.org/10.1111/j.13652672.2010.04820.x

25. M. E. J. Al-Defiery and A. F. Merjan, Mesopotamia Environ. J., 1(2015) 18. https://www.iasj.net/iasj?func=article \&aId=1 71332 